\title{
Acute Kidney Injury with Polyuria in a Patient with HIV
}

Samuel A Silver MD, Robert Richardson MD

\begin{abstract}
About the Authors
Samuel Silver is a nephrologist and quality improvement fellow at St. Michael's Hospital, Toronto, Ontario. Robert Richardson is a nephrologist and clinician teacher at Toronto General Hospital, Toronto, Ontario.Correspondence may be directed tosam.silver@utoronto.ca.
\end{abstract}

\section{Summary}

We describe the case of a 30-year-old man with HIV with an elevated creatinine and three litres per day of urine output. Using this patient as a framework, we review a diagnostic approach to acute kidney injury with polyuria. This case emphasizes the importance of a complete diagnostic evaluation of acute kidney injury. Without this approach, it would have been easy to attribute the patient's acute kidney injury to his HIV and necrotizing peri-anal infection, instead of the true lifethreatening cause.

\section{Case}

A 30-year-old Caucasian man presented to hospital with fever and peri-anal abscesses. He suffered from chronic peri-anal fistulas and had previously undergone five fistulotomies. He also had a long-standing history of HIV treated with anti-retroviral therapy, but stopped his therapy six months previously. He had no history of opportunistic infections, and his most recent CD4 (T-cell) count taken two months prior to presentation was 460 cells $/ \mathrm{mm}^{3}$. His CD4 count on admission to hospital was 77 cells $/ \mathrm{mm}^{3}$. Abdominal imaging revealed intramuscular and fascial air throughout the right leg and pelvic muscles. There was loculated gas within the right mesorectum/presacral space. He was diagnosed with necrotizing fasciitis from a peri-rectal source and underwent a right above-knee amputation along with loop ileostomy. Cultures from the operating room later grew Streptococcus anginosis, and he was treated with appropriate antibiotics. He required several more debridements while in hospital and had a very slow convalescence.

\section{Onset of Acute Kidney Injury}

While the patient recovered, routine blood work (complete blood cell count $[\mathrm{CBC}]$, electrolytes, and creatinine) was done on a weekly basis. Three months after his first surgery, his serum creatinine was noted to be $250 \mu \mathrm{mol} / \mathrm{L}$ from a baseline the previous week of $50 \mu \mathrm{mol} / \mathrm{L}$. A nephrology consultation (which included the authors) was requested.

Further history revealed that the patient was eating well with no significant gastrointestinal symptoms. His medication list included ritonavir, emtricitabine, tenofovir, atazanavir, metoprolol, cotrimoxazole prophylaxis, hydromorphone, and gabapentin. He had received no new nephrotoxic drugs such as non-steroidal anti-inflammatories or aminoglycosides. His last abdominal computed tomography (CT) scan, done three weeks earlier, reported normal-appearing kidneys.

Physical examination revealed a heart rate of 80 beats per minute (BPM) and blood pressure 140/90. His jugular venous pressure was below the sternal angle when supine. His lungs were clear. There was no ascites or peripheral edema. He had a foley catheter in place, and his urine output for the past several days averaged 3.5-4 L daily.

In addition to the serum creatinine of $250 \mu \mathrm{mol} / \mathrm{L}$, his hemoglobin was stable at $75 \mathrm{~g} / \mathrm{L}(131 \mathrm{~g} / \mathrm{L}$ at admission $)$, white blood cell (WBC) count $8.4 \times 10^{9} / \mathrm{L}$, platelets $320 \times 10^{9} / \mathrm{L}, \mathrm{Na}$ $131 \mathrm{mmol} / \mathrm{L}, \mathrm{K} 4.2 \mathrm{mmol} / \mathrm{L}, \mathrm{HCO} 328 \mathrm{mmol} / \mathrm{L}, \mathrm{Cl} 94 \mathrm{mmol} / \mathrm{L}$. The low hemoglobin was secondary to anemia of acute illness from multiple surgeries and infection; there was no evidence of ongoing blood loss or hypotension that could have precipitated 
acute tubular necrosis. Urinalysis from a catheter specimen revealed red blood cells and leukocytes but no protein or casts. The urine osmolality was $147 \mathrm{mosmol} / \mathrm{kg}$, and the urine electrolytes were $\mathrm{Na} 44 \mathrm{mmol} / \mathrm{L}, \mathrm{K} 7 \mathrm{mmol} / \mathrm{L}$, and Cl $44 \mathrm{mmol} / \mathrm{L}$.

\section{Identifying the Cause of Acute Kidney Injury with Polyuria}

The presence of acute kidney injury (AKI) with polyuria prompted additional investigations. The serum calcium was found to be $3.9 \mathrm{mmol} / \mathrm{L}$ (normal range $2.2-2.6 \mathrm{mmol} / \mathrm{L}$ ), with an albumin of $25 \mathrm{~g} / \mathrm{L}$. Further testing into the etiology of his hypercalcemia revealed that parathyroid hormone, $25-\mathrm{OH}$ vitamin $\mathrm{D}$, and $1,25-\mathrm{OH}$ vitamin $\mathrm{D}$ were low or undetectable. An abdominal ultrasound showed moderate to severe bilateral hydronephrosis. Bilateral nephrostomy tubes were placed to relieve the urinary tract obstruction, and the patient was treated with intravenous normal saline and pamidronate for the hypercalcemia. One week after initial nephrology consultation, his calcium was $2.14 \mathrm{mmol} / \mathrm{L}$ and creatinine $68 \mu \mathrm{mol} / \mathrm{L}$. His urine output decreased to $1.5 \mathrm{~L}$ per day.

CT imaging (Figure 1) of his thorax, abdomen, and pelvis revealed extensive lytic bone lesions involving the manubrium, left scapula, thoracic and lumbar spine, ribs, pubic rami, pubic symphysis, and iliac bones. There were multiple enlarged abdominal lymph nodes, with the largest measuring $1.5 \mathrm{~cm}$. The bladder wall was diffusely thickened. These findings were new compared to the CT imaging from four weeks earlier. The radiologist's report suggested bacillary angiomatosis as the most likely diagnosis.

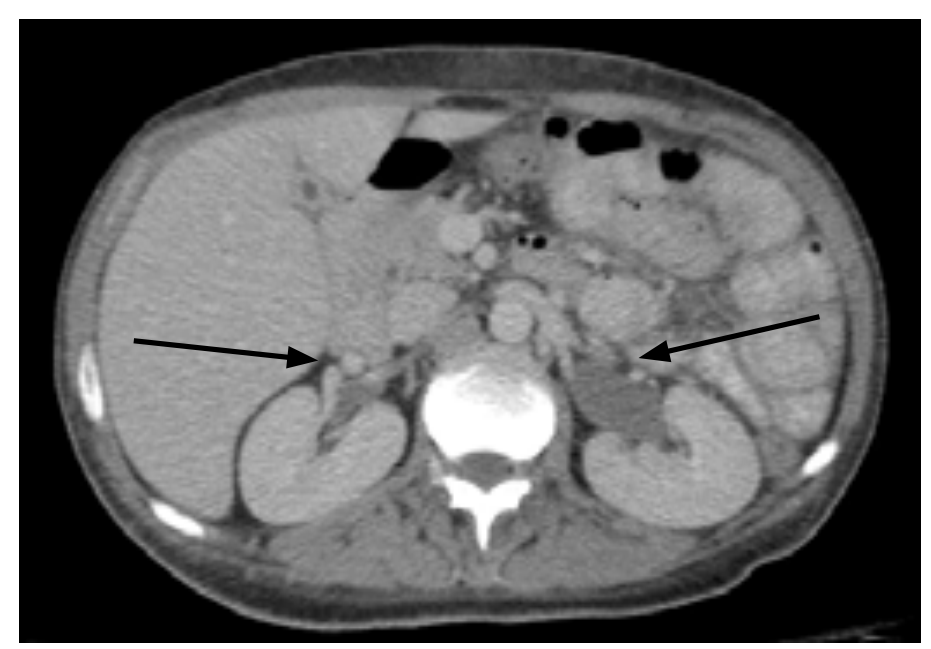

Figure 1: CT scan of the patient's abdomen showing bilateral hydronephrosis. The left ureter is dilated more than the right on this section (arrows). Other CT scan sections not shown here, revealed diffuse bladder wall thickening and numerous lytic lesions involving the pubic rami, iliac bones, and vertebral bodies.
The infectious disease service was consulted, but they felt bacillary angiomatosis was unlikely given the absence of cutaneous lesions. Bartonella serology was also ordered and was negative. We subsequently revisited the CT scan findings of lytic bone lesions (bone biopsy) and a diffusely thickened bladder (urine cytology). A bone biopsy of the left ilium showed infiltrative squamous cells with a desmoplastic response that was diagnostic of metastatic squamous cell carcinoma. The primary site was unclear from the bone biopsy, and the possibilities mentioned by the pathologist included upper aerodigestive tract, esophagus, lung, skin, bladder, and perineal. Urine cytology revealed abnormal keratinized cells suspicious for primary bladder malignancy. A cystoscopy was planned to confirm the suspicion of metastatic bladder cancer, but the patient decompensated due to a small bowel obstruction (SBO). The SBO was a result of a de-functioning ileostomy and surgical adhesions and not related to his malignancy. The SBO led to a bacterial peritonitis and sepsis, and the patient passed away shortly thereafter (less than two weeks after the onset of his AKI).

\section{Discussion}

The 30-year-old patient started with a necrotizing peri-anal infection, was followed by an episode of AKI with polyuria, and concluded with a likely diagnosis of metastatic bladder cancer. These three conditions warrant further discussion to review important learning points.

\section{Necrotizing Peri-Anal Infections in Patients with HIV}

Anorectal disease occurs in $6 \%-34 \%$ of patients with HIV. Peri-anal sepsis is known to be more prevalent in the HIV population $(4.0 \%)$, compared with the general population (1.6\%). ${ }^{1}$ Fistula and abscess are the most common forms of perianal sepsis in the HIV population. Complications of peri-anal sepsis include necrotizing fasciitis of the genital area, perineum, and peri-anal region (Fournier's gangrene), and there are several case reports involving patients with HIV..$^{2-5}$

The largest series of HIV peri-anal sepsis retrospectively reviewed 50 cases over a 10 -year period. ${ }^{1}$ Seven $(14 \%)$ of the patients had serious septic complications, consisting of Fournier's gangrene (4) and metastatic abscesses (3). All four patients with Fournier's gangrene were men aged between 34 and 41 years. Their mean CD4 counts were 200 cells $/ \mathrm{mm}^{3}$, compared to 350 cells $/ \mathrm{mm}^{3}$ for patients with uncomplicated peri-anal sepsis. The initial presentations included severe anal pain and fever. Previous treatment for peri-anal fistula had occurred in all four patients. Cultures revealed mixed flora in all patients (Klebsiella pneumoniae, Streptococcus group C, Streptococcus milleri, 
Proteus mirabilis, and various anaerobes). In three patients, the necrotizing fasciitis was progressive and a diverting colostomy was performed. All four patients survived to hospital discharge. The median post-operative survival time for the entire cohort was 2.8 years.

Our case demonstrates a classic presentation of Fournier's gangrene in a patient with HIV. The patient also had several common risk factors, including male sex, young age, low CD4 count, and previous treatment for peri-anal fistula. The only atypical feature was that a single organism was isolated (Streptococcus anginosis); however, Streptococcus anginosis is a common cause of necrotizing fasciitis. ${ }^{6}$ The severity of perianal sepsis and its complications emphasizes the importance of adequately treating asymptomatic fistulas in patients with HIV with surgical referral and fistulotomy.

\section{Cause of AKI and Polyuria}

The most striking and unusual feature of the patient's AKI was polyuria, despite appearing to have significant volume depletion. Table 1 shows some of the causes of AKI with polyuria. These causes are not specific to patients with HIV, and we approached the diagnostic work-up as we would for a patient without HIV.

\section{Table 1. Causes of Acute Kidney Injury with Polyuria}

\begin{tabular}{|c|c|}
\hline $\begin{array}{c}\text { Water Diuresis } \\
\text { (under } 1000 \text { mosmol/day) }\end{array}$ & $\begin{array}{c}\text { Solute Diuresis } \\
\text { (over } 1000 \text { mosmol/day) }\end{array}$ \\
\hline $\begin{array}{l}\text { Central diabetes insipidus } \\
\text { - Posterior pituitary trauma or } \\
\text { resection (with no access to } \\
\text { water) } \\
\text { - Hypoxic encephalopathy post- } \\
\text { cardiac arrest } \\
\text { - Granulomatosis with polyangiitis }\end{array}$ & \multirow[t]{2}{*}{$\begin{array}{l}\text { - Glucose (diabetic ketoacidosis, } \\
\text { hyperosmolar hyperglycemic } \\
\text { state) } \\
\text { - Urea (high-protein feeds) } \\
\text { - Mannitol } \\
\text { - Release of bilateral urinary tract } \\
\text { obstruction }\end{array}$} \\
\hline $\begin{array}{l}\text { Nephrogenic diabetes insipidus } \\
\text { - Drugs (lithium, amphotericin, } \\
\text { ifosfamide, analgesic abuse } \\
\text { nephropathy) } \\
\text { - Electrolyte disorders } \\
\text { (hypercalcemia, hypokalemia) } \\
\text { - Pyelonephritis } \\
\text { - Bilateral urinary tract obstruction } \\
\text { - Sickle cell disease } \\
\text { - Sjogren's disease } \\
\text { - Renal amyloidosis }\end{array}$ & \\
\hline
\end{tabular}

Polyuria is defined as urine output over $3 \mathrm{~L}$ per day and may be due primarily to water loss (with normal solute excretion) or to solute diuresis driven by the excretion in the urine of larger than normal amounts of osmoles such as glucose, urea, or mannitol. Water diuresis can be separated from solute diuresis by calculating the 24-hour solute excretion rate from the urine flow rate and urine osmolality. A value greater than $1,000 \mathrm{mosmol} /$ day suggests a solute diuresis whereas a value less than $1,000 \mathrm{mosmol} /$ day suggests a water diuresis. Our patient was passing $500 \mathrm{mosmol} /$ day. This suggested that the cause of the polyuria was likely due to a water diuresis.

Both bilateral urinary tract obstruction and hypercalcemia were identified as the causes of the patient's water diuresis. It is often assumed that obstructed patients should be oliguric or anuric; however, patients with a partial obstruction can have a normal or increased urine output due to tubular damage causing a concentrating defect from decreased tubular reabsorption. Hypercalcemia causes polyuria by activating the calcium-sensing receptor in the thick ascending limb of the Loop of Henle. This results in decreased resorption of sodium and chloride in the Loop of Henle and decreases the kidney's ability to concentrate urine, similar to furosemide. ${ }^{7}$ Therefore, AKI with polyuria in this patient was explained by both urinary tract obstruction and hypercalcemia.

Physicians are inclined to favour a unifying diagnosis over two or more unrelated diagnoses in perplexing cases such as this, but we found it difficult to imagine a single process that would cause urinary tract obstruction and hypercalcemia in this age group and over a relatively brief period of time. We therefore investigated the urinary obstruction and hypercalcemia independently, with no preconceived ideas of how they might intersect. Similar to our radiology colleagues, we were particularly interested in infectious etiologies, given the patient's HIV history. Instead, the investigations revealed metastatic squamous cell carcinoma, with the bladder as the likely primary site.

\section{HIV and Risk of Malignancy}

Should the patient's history of HIV infection have caused us to more seriously consider malignancy as our leading diagnosis? Several large prospective multicentre observational cohort studies $^{8,9}$ and a meta-analysis ${ }^{10}$ have followed over 400,000 patients with HIV over 10-year periods. These studies suggest that patients with HIV have an increased risk of non-AIDSdefining cancer (NADC) compared to the general population..$^{8-10}$ The cancers that account for most of this risk include anal, Hodgkin's lymphoma, vaginal, liver, penile, leukemia, laryngeal, lung, oropharyngeal, and brain (Table 2). ${ }^{8-10}$ Thus it appears the current literature does not support an increased risk of bladder cancer in patients with HIV above the incidence rate in the general population.

A single retrospective case series identified 11 cases of bladder 
cancer in patients with HIV over a 15 -year period. ${ }^{11}$ The patients ranged in age from 33 to 67 years. Ten of these cases were due to transitional cell carcinoma, which is not surprising given that it accounts for $90 \%$ of all bladder cancers. The mean CD4 count was $280 \mathrm{cells} / \mathrm{mm}^{3}$, and 9 of 11 patients were on anti-retroviral therapy. All patients diagnosed with metastatic disease died within seven months of presentation.

Our case represents the youngest-described patient with HIV and bladder cancer reported to date. Given our patient's age and the aggressive course of the malignancy, it is tempting to attribute the bladder cancer to his immunosuppressed state from HIV. This was compounded by the patient's cessation of antiretroviral therapy six months prior to presentation. A Chinese registry study of over 3,500 patients found that most malignant diseases in patients with HIV occur at a more advanced stage and with shorter survival time; thus malignancy in patients with HIV is associated with an aggressive course. ${ }^{12}$ Our patient's rapid presentation and spread was particularly aggressive; these features suggest that HIV might have been a significant risk factor, even though bladder cancer is not a typical NADC.

\section{Table 2: Incidence of Non-AIDS-Defining-Cancers in} Patients with HIV

\begin{tabular}{|l|l|}
\multicolumn{1}{|c|}{ Cancer Type } & \multicolumn{1}{c|}{\begin{tabular}{c}
\multicolumn{1}{c|}{ Standardized Incidence Ratio (SIR) } \\
(95) CI)
\end{tabular}} \\
\hline Bnal & $28.75(21.60-38.30)$ \\
\hline Brain & $0.75(0.43-1.32)$ \\
\hline Breast & $2.18(1.29-3.68)$ \\
Colorectal & $1.03(0.89-1.20)$ \\
\hline Esophageal & $0.92(0.78-1.08)$ \\
\hline Hodgkin lymphoma & $1.62(1.20-2.19)$ \\
\hline Laryngeal & $11.03(8.43-14.40)$ \\
\hline Leukemia & $2.72(2.29-3.22)$ \\
\hline Liver & $3.20(2.51-4.09)$ \\
\hline Lung & $5.22(3.32-8.20)$ \\
\hline Melanoma & $2.72(1.91-3.87)$ \\
\hline Orophyrangeal & $1.24(1.04-1.48)$ \\
\hline Ovarian & $2.32(1.65-3.25)$ \\
\hline Penile & $1.63(0.95-2.80)$ \\
\hline Prostate & $4.42(2.77-7.07)$ \\
\hline Renal & $0.70(0.55-0.89)$ \\
\hline Stomach & $1.50(1.23-1.83)$ \\
\hline Testicular & $1.90(1.53-2.36)$ \\
\hline Thyroid & $1.35(1.01-1.79)$ \\
\hline Vaginal & $0.84(0.51-1.40)$ \\
\hline & $6.45(4.07-10.20)$ \\
\hline
\end{tabular}

The SIR is obtained by dividing the observed number of cases by the expected number of cases. The expected number is calculated using data from a larger reference population.

${ }^{*}$ Adapted from Grulich et al. ${ }^{10}$

\section{Conclusion}

A classic presentation of Fournier's gangrene in a patient with HIV resulted in a surprising diagnosis of metastatic squamous cell carcinoma, likely due to a bladder primary. The key observation that led to this unusual diagnosis was the presence of AKI with polyuria. This case emphasizes the importance of a complete diagnostic evaluation of AKI, particularly when the patient has polyuria. Without this approach, it would have been easy to attribute the patient's AKI to more common causes, such as acute tubular necrosis from Fournier's gangrene. Instead, we identified a rapidly progressive and advanced bladder cancer and report the youngest case of bladder cancer in a person with HIV.

\section{References}

1. Consten EC, Slors JF, Danner SA, et al. Severe complications of perianal sepsis in patients with human immunodeficiency virus. Br J Surg 1996;83:778-80.

2. McKay TC, Waters WB. Fournier's gangrene as the presenting sign of an undiagnosed human immunodeficiency virus infection. J Urol 1994;152:1552-4.

3. Caird J, Abbasakoor F, Quill R. Necrotising fasciitis in a HIV-positive male: an unusual indication for abdomino-perineal resection. Ir J Med Sci 1999;168:251-3.

4. Nelson MR, Cartledge J, Barton SE, et al. Fourniers gangrene following hyfrecation in a male infected with the human immunodeficiency virus. Genitourin Med 1992;68:401-2.

5. Murphy M, Buckley M, Corr J, et al. Fournier's gangrene of scrotum in a patient with AIDS. Genitourin Med 1991;67:339-41.

6. Anaya DA, Dellinger EP. Necrotizing soft-tissue infection: diagnosis and management. Clin Infect Dis 2007;44:705-10.

7. Hebert SC, Brown EM. The scent of an ion: calcium-sensing and its roles in health and disease. Curr Opin Nephrol Hypertens 1996;5:45-53.

8. Franceschi S, Lise M, Clifford GM, et al. Changing patterns of cancer incidence in the early- and late-HAART periods: the Swiss HIV Cohort Study. Br J Cancer 2010;103:416-22.

9. Patel P, Hanson DL, Sullivan PS, et al. Incidence of types of cancer among HIV-infected persons compared with the general population in the United States, 1992-2003. Ann Intern Med 2008;148:728-36.

10. Grulich AE, van Leeuwen MT, Falster MO, et al. Incidence of cancers in people with HIV/AIDS compared with immunosuppressed transplant recipients: a meta-analysis. Lancet 2007; 370:59-67.

11. Gaughan EM, Dezube BJ, Bower M, et al. HIV-associated bladder cancer: a case series evaluating difficulties in diagnosis and management. BMC Urol 2009;9:10.

12. Zhang YX, Gui XE, Zhong YH, et al. Cancer in cohort of HIV-infected population: prevalence and clinical characteristics. J Cancer Res Clin Oncol 2011;137:609-14. 